\title{
Relations between Brain and Cognitive Development
}

\author{
Kurt W. Fischer \\ University of Denver and Harvard University
}

\begin{abstract}
FISChER, KURT W. Relations between Brain and Cognitive Development. ChILD DeVELOPMENT, 1987, 58, 623-632. Goldman-Rakic reports important new data on cortical development in rhesus monkeys. Some of her findings, especially concurrent cortical synaptogenesis, may be related to cognitive capacities that develop in infancy. The developmental pattern of concurrent synaptogenesis in rhesus is consistent with a straightforward model of relations between brain and cognitive development: Concurrent synaptogenesis is hypothesized to lay the primary cortical foundation for a series of developmental levels in middle infancy that have been empirically documented in both human and rhesus infants. Other general brain changes, especially in the electroencephalogram, also seem to correlate with these levels, as well as with other levels that develop at other periods. In the simplest form of the model, these several factors all show synchronous developmental discontinuities at the time of emergence of a level. Specific research methods are available for specifying when discontinuities occur in development of both brain and behavior.
\end{abstract}

Obviously brain development relates to cognitive development. Developmental scientists generally make that assumption when they consider relations between brain and behavior. Yet it has proved to be difficult to establish specific developmental relations. Global correlations exist, of course: Myelination occurs progressively throughout infancy, childhood, and even adolescence (Gibson, 1977; Yakovlev \& Lecours, 1967). Both dendritic branching and synaptic density change systematically during infancy (Conel, 19391963; Goldman-Rakic, 1987, in this issue; Huttenlocher, 1979). During the same periods, children become progressively more intelligent by most criteria. Unfortunately, such correlations say little about real links between brain and behavioral development because they are too global. Any factors that show general change with age will correlate with each other, as every statistics book demonstrates. To be meaningful, a relation must be specified more precisely. For example, what particular changes in the brain relate to what specific new capacities emerging in children?

In the past, the state of research in both cognitive development and brain development made it difficult to test hypothesized specific relations. For cognitive development, researchers had difficulty agreeing on even the ages of emergence of major capacities (Biggs \& Collis, 1982; Flavell, 1982; Gelman, 1978). For brain development, researchers had produced relatively few data on specific neural changes that might relate to significant cognitive developments in human beings or other primates.

As Goldman-Rakic (in this issue) suggests, however, the field of developmental neuroscience seems to have entered a new era. At the same time, the field of cognitive development has also advanced, with major new achievements in theory and method. As a result of these advances in the two disciplines, there is genuine promise of the discovery of meaningful links between specific brain and cognitive developments. Indeed, two of the major sets of findings reported by Goldman-Rakic seem to have important implications for links between brain and cognitive developments.

One major set of findings is the provision of a relatively complete "wiring diagram" for a region of the prefrontal cortex in rhesus monkeys, especially in terms of its relation to performance on a standard cognitive assessment tool, the delayed-response task (Gold-

Preparation of this article was supported by a fellowship from the Cattell Fund and grants from the Spencer Foundation and the Carnegie Corporation. The statements made and views expressed are solely the responsibility of the authors. I would like to thank Robert G. Anderson, Eric Fischer, Sandra Pipp, Sam Rose, and Sheldon White for their contributions to the concepts and data presented and Bruce Pennington and Linda Crnic for their thoughtful editorial suggestions. The author is now at Harvard University. Address reprint requests to Kurt W. Fischer, Larsen Hall, Appian Way, Harvard University, Cambridge, MA 02138.

[Child Development, 1987, 58, 623-632. ( 1987 by the Society for Research in Child Development, Inc. All rights reserved. 0009-3920/87/5803-0022\$01.00] 
man-Rakic, 1986). To my knowledge, this is the first such description of part of the neural basis of an intelligent behavior.

The second major set of findings is the phenomenon of concurrent cortical synaptogenesis (Rakic, Bourgeois, Eckenhoff, Zecevic, \& Goldman-Rakic, 1986). Neural connections between parts of the cerebral cortex have already begun to form almost 2 months before birth in rhesus, yet at birth rhesus behavior is still far from the adult form. What happens during infancy is the formation of synapses, the links by which neurons communicate. Indeed, synapse formation shows a sharp spurt and subsequent drop, and this pattern occurs across all areas investigated in the cortex. There is no obvious developmental sequence in which one area shows synaptogenesis before another. It is this pattern that GoldmanRakic and her colleagues call concurrent synaptogenesis.

As Goldman-Rakic points out, concurrent synaptogenesis relates closely in time to the appearance of an important cognitive advance on the delayed-response task, which involves what Piaget (1937/1954) called object permanence. This task requires the coordination of a number of cortical functions, and consequently it makes sense that synaptogenesis throughout the cortex should correspond to an advance in performance on the task. Indeed, a number of other skills develop at approximately the same age, and all require a similar coordination of a number of cortical functions.

Considered together with recent research in cognitive development, these findings suggest two classes of hypotheses about relations between brain and cognitive developments. First, the spurt and subsequent drop in synaptogenesis may relate closely to certain key cognitive capacities that emerge in middle infancy. I will suggest a specific model of these relations as well as methods for testing them. Second, the development of new general cognitive capacities seems to involve concurrent changes in numerous areas of the cortex. Apparently, the coordination of the functions of diverse regions is necessary for major cognitive advances.

\section{A Relation between Concurrent Synaptogenesis and Sensorimotor Development}

Concurrent synaptogenesis may lay the primary cortical foundation for important cognitive capacities that emerge in infancy. During the period of synaptogenesis, new cognitive capacities appear, and there also seems to be a general spurt in brain growth, as measured by global indexes other than synaptogenesis itself.

Four levels of sensorimotor development.-With recent advances in cognitivedevelopmental method and theory, researchers have found clear-cut evidence for at least four periods of rapid behavioral change in infant development, often called developmental levels or transitions. Data from a number of different laboratories have led to similar conclusions (Corrigan, 1983; Fischer \& Silvern, 1985; McCall, 1983; Seibert, Hogan, \& Mundy, 1984; Uzgiris, 1976). Based on longitudinal assessments with standardized tests, McCall, Eichorn, and Hogarty (1977) found these rapid changes at 2-4 months, 7-8 months, 12-13 months, and 18-21 months in human infants. (There may be additional periods of rapid change in the first 4 months; see Fischer, 1980, and Fischer \& Hogan, in press.)

Each of these periods of rapid change appears to mark the emergence of a specific new cognitive capacity, as summarized in Table 1 . The new capacity does not lead to instantaneous change in all skills, since it must be applied to each individual skill to reconstruct it in a more complex, advanced form. In this way, many skills (but not all) will advance within a relatively brief age period (Fischer \& Pipp, 1984). Concurrent synaptogenesis may provide the cortical basis for these levelspecific capacities.

At 2-4 months, human infants become able to reliably control variations in a single action in the service of a simple goal. For example, a 4-month-old girl can keep her gaze on a face as it moves around in front of her, or she can voluntarily grasp a rattle that is lying next to her, pursuing it until she gets hold of it. Before 2 months, infants show little evidence of the capacity to reliably adopt such actions.

At 7-8 months, infants demonstrate the ability to consistently relate a few actions in a single unit. An 8-month-old boy can skillfully pull a string to make a mobile jiggle, and he can look at a toy and use what he sees to guide his hand to grasp the toy in many different locations. The delayed-response task studied by Diamond and Goldman-Rakic (1983; Diamond, 1985) involves this kind of eye-hand coordination. Other types of relations of actions also develop at this age, such as the coordination of vocalization and hearing in the repetition of simple sounds such as "mamama" (Ramsay, 1984) and the coordina- 
TABLE 1

Four Documented SENSORIMotor LeVels in Human INFANTS

\begin{tabular}{|c|c|c|}
\hline Level & Some Characteristic Behaviors & $\begin{array}{l}\text { Modal Age of } \\
\text { Emergence }\end{array}$ \\
\hline $\begin{array}{l}\text { Single sensorimotor } \\
\text { actions } \ldots \ldots \ldots \ldots\end{array}$ & $\begin{array}{l}\text { Single actions and perceptions; first social- } \\
\text { emotional responsiveness }\end{array}$ & 2-4 months \\
\hline $\begin{array}{l}\text { Relations of a few } \\
\text { sensorimotor actions..... }\end{array}$ & $\begin{array}{l}\text { Coordination of means and end; skilled eye-hand } \\
\text { coordination; attachment relationship with } \\
\text { caretaker }\end{array}$ & 7-8 months \\
\hline $\begin{array}{l}\text { Systems of several } \\
\text { sensorimotor actions... }\end{array}$ & $\begin{array}{l}\text { Complex means-ends variations in action; } \\
\text { location of characteristics in objects and } \\
\text { people; use of single words }\end{array}$ & $11-13$ months \\
\hline Representations.......... & $\begin{array}{l}\text { Symbolization of people and objects; vocabulary } \\
\text { spurt; multiword utterances }\end{array}$ & 18-21 months \\
\hline
\end{tabular}
(1976).

NOTE.-This table is based on Fischer and Silvern (1985), McCall, Eichorn, and Hogarty (1977), and Uzgiris

tion of two or more looking acts to produce perception of a visual pattern (Bertenthal, Campos, \& Haith, 1980).

By 12-13 months, infants show the capacity to relate a number of actions in a complex system. A 13-month-old girl can facilely move an object through many positions, using what she sees to guide what she does with the object, and she can experiment with different ways of holding an object until she finds one that accomplishes some desired goal, such as dropping a ball so that it falls into a small hole in a toy box. In the delayed-response task, children become capable of finding the hidden object in the face of multiple hidings, so long as they can actually see the object being covered the last time it is hidden.

In the middle of the second year, at 1821 months, toddlers develop the ability of representation or symbolization, as originally described by Piaget (1946/1951). Moving beyond action systems, they can cognitively evoke an object, event, or person that is not actually present, pretending that a doll is walking across the table or talking about what their uncle did a few days before (Watson \& Fischer, 1977). At the same time they begin to speak sentences and show a large spurt in vocabulary (Bates, Benigni, Bretherton, Camaioni, \& Volterra, 1979; Bloom, 1973; Corrigan, 1983).

Although the behavioral evidence for monkeys is less complete than that for human infants, assessments of sensorimotor development similar to those used by Piaget (1937/ 1954) and Uzgiris and Hunt (1975) indicate similar developmental sequences in monkeys and people (Chevalier-Skolnikoff, 1977; Diamond \& Goldman-Rakic, 1986; Parker \& Gibson, 1979). The most complete behavioral data involve stumptail macaques, a species closely related to rhesus macaques (which were studied in Goldman-Rakic's research). In general, both types of monkeys show developmental sequences similar to those of human infants, except that they produce specifies-specific behaviors such as climbing and lip smacking and they show less exploration of the properties of objects.

The macaques show only the first three of the four sensorimotor levels as evidenced by the developmental sequences that have been documented. I know of no test of whether they demonstrate periods of rapid change with the emergence of each level. The first level, single actions, appears at 1 month of age. The second level, simple relations of actions, develops at 2 months. This is the same age that Goldman-Rakic (1987, in this issue) finds emergence of this level in the delayed-response task in rhesus, as well as the age that she specifies for the start of the spurt in synaptogenesis. Also, she lists a long series of other behaviors that develop at this age. The third level, systems of actions, appears at 4-41/2 months, which is the age at which rhesus show the most advanced performance in the delayed-response task as well as the end of the synaptogenetic spurt.

Synaptogenesis and relations of actions.-Goldman-Rakic hypothesizes that the advance in search in the delayed-response task develops as a result of concurrent synaptogenesis. The formation of new synapses and 


\section{Child Development}

the subsequent deletion of extra synapses bring the capacity to recall information about where an object was hidden before, which produces the change in search. She calls this capacity representation, because the monkey can recall information that is not directly available in the stimulus array. This sense of representation is different from the representation or symbolization that characterizes the fourth level of sensorimotor development.

In the cognitive-developmental literature, the term "representation" is used in two distinct ways. Researchers with an information-processing orientation typically use it as Goldman-Rakic does to refer to recall memory in general, including the ability to remember where an object was hidden in the delayedresponse task. Those in the Piagetian tradition, on the other hand, use it to refer to a more complex recall capacity-the ability to evoke an object, person, or event that is not present, as evidenced for example by pretending that a block is a dog walking across the table. The information-processing meaning requires that the organism bring to bear some information that is not present in the stimulus display at the moment. The Piagetian meaning, on the other hand, requires the evocation (interiorized recreation or imitation) of some entity that is absent, such as the dog walking across the table, the uncle who made a funny face yesterday, or the favorite toy truck (Fischer \& Jennings, 1981; Piaget, 1946/1951). Rhesus never develop this representational capacity of the fourth level, but at the second and third sensorimotor levels they do develop representation in the sense of recall (Fischer, 1982; Parker \& Gibson, 1979).

A straightforward extension of GoldmanRakic's hypothesis is that concurrent synaptogenesis relates to the emergence and consolidation of the second and third sensorimotor levels. The delayed-response task is an index of the second level in infancy, relations of actions. At this level, infants develop the capacity to coordinate two or more sensorimotor actions in a single, integrated skill or scheme, including the ability to use one action to recall a second one (Case, 1985; Fischer, 1980; McCall et al., 1977; Uzgiris, 1976).

According to this neo-Piagetian analysis, here is what happens in the delayed-response task. With the capacity to relate actions, infants begin to search successfully for objects placed under a screen. In carrying out that search, however, they demonstrate what is called the $A \bar{B}$ error: Under certain conditions, they systematically reach under the screen where they found the object on the previous trial instead of under the screen where they just saw the object disappear. This behavior in search was originally reported by Piaget (1937/1954), and hundreds of studies by other researchers have documented and extended his findings (Uzgiris \& Hunt, 1975).

In the relation of actions for the delayedresponse task, infants coordinate looking at the disappearing object, looking at the screen, and grasping the object under the screen; and in doing so, they coordinate where they found the object on the previous trial with where they search on the present trial. It is precisely this coordination that leads to searching under the incorrect screen (the one correct on the previous trial).

At the end of the period of concurrent synaptogenesis in rhesus, the third sensorimotor level is emerging. Infants come to be able to control systems of actions, involving complex relations among a number of actions, and such complex relations produce a great increase in the complexity of search behavior, including coping with long delays in the delayed-response task (McCall et al., 1977; Uzgiris, 1976).

Another way of stating this relation is that discontinuities in the synaptogenetic spurt correlate with the second and third levels. The start of the peak in synaptogenesis correlates with the second level, and the end of the peak correlates with the third level. I will argue that such discontinuities in concurrent synaptogenesis and in other aspects of brain growth relate to each of the levels of sensorimotor development. Recall that each level is also indexed by discontinuities, spurts in behavioral change. Thus, it is necessary to discuss methodological issues about testing for discontinuities before outlining the braingrowth model and the research it suggests.

\section{Methods of Assessing for Levels}

Discontinuities, such as spurts and drops in developmental curves, seem to be one of the most straightforward and easily assessed indexes of developmental levels. A discontinuity is an abrupt change in the slope of a developmental curve. This meaning of discontinuity refers solely to the form of the developmental function. It has no direct implications for other issues often labeled with the same term, such as the degree of stability (continuity) or instability (discontinuity) in individual differences during development (Bornstein \& Sigman, 1986). 
Several methods have been devised for investigating discontinuities and relating them across different measures. The ensuing discussion of these methods is based on the following sources, where the methods are described in more detail: Fischer and Canfield (1986), Fischer, Pipp, and Bullock (1984), and McCall (1983). Wohlwill's (1973) classic discussion of developmental methods is also relevant.

Guidelines for research.-Testing for developmental discontinuities within and across domains is straightforward, provided that certain simple guidelines are followed. Four key methodological issues are age sampling, the sensitivity of the developmental scale, the range of domains assessed, and the influence of testing conditions. The research from Goldman-Rakic's laboratory has broken new ground, and so of course it could not be designed to anticipate all these issues. Future research, however, will more satisfactorily answer important developmental questions if it deals with these issues. Most obviously needed are more precise assessments of the developmental course of synaptogenesis and its relation to the behavioral changes characteristic of the sensorimotor levels.

First, detection of a spurt or drop requires a good clock, one that can detect the rapidity of the change. Ages must be sampled frequently enough to provide multiple assessments before, during, and after the period of the hypothesized spurt or drop. For example, if three developmental levels are hypothesized to emerge in the first year in human babies, then assessments must be made at least once a month to reliably detect the period of the discontinuities. Such frequent age sampling is needed for both synaptogenesis and behavioral development.

Second, detection of discontinuities requires not only a good clock but also a good ruler, a scale that is sensitive to developmental change. The measure of synaptic density appears to provide such a ruler, but the delayed-response task probably does not. The best cognitive assessments typically form a relatively continuous developmental scale of cognitive complexity. One of the best ways of devising such a scale is to use a number of tasks within the same domain that vary in cognitive complexity (Corrigan, 1983; Uzgiris \& Hunt, 1975).

A single task will seldom provide a good ruler, primarily because it produces such a limited sample of behavior. If a single task is to be used, the delayed-response task is a good choice for the age period under study, but its limits should be recognized. Different tasks generate different developmental patterns, even when they assess what appears to be a single content domain such as search (Jackson, Campos, \& Fischer, 1978). This task effect is one of the best documented phenomena in cognitive development (Biggs \& Collis, 1982; Flavell, 1982; Uzgiris \& Hunt, 1975). Some research on errors suggests that a single task may only index behaviors that are close to the level of complexity of that task. For example, on a task that is far beyond children's developmental level, they often do not demonstrate abilities that they show easily on simpler tasks (Fischer \& Roberts, 1986; Roberts, 1981). Multi-task scales for search that eliminate these problems are available and have been used extensively in developmental research (Corrigan, 1983; Uzgiris \& Hunt, 1975).

Third, just as assessment of cortical functioning requires testing diverse areas of the cortex, assessment of cognitive functioning requires testing diverse domains of behavior. Performance in one task domain is not representative of cognitive development in general. Although each developmental level does seem to produce rapid changes in performance on many tasks in many domains, there is still great variability across domains.

Fourth, a cognitive-developmental assessment should include a range of testing conditions. Factors such as practice, familiarity, and memory requirements produce wide variations in the forms of developmental curves even when the same tasks are used. Only a range of testing conditions, including for example both low- and high-practice conditions, can provide an accurate general portrait of cognitive development.

The developmental pattern of synaptogenesis.-For research on synaptogenesis, two key issues are the sampling of ages and the assessment of diversity across cortical regions. The data reported by Goldman-Rakic and her colleagues (Rakic et al., 1986) provide frequent-enough samples to give an initial rough estimate of the developmental pattern of synaptogenesis.

One of the most interesting charcteristics of cortical synaptogenesis is its concurrence across cortical areas, as Goldman-Rakic (1987, in this issue) points out: It shows approximately the same developmental function across all assessed areas of the cortex, even though it would have been reasonable to ex- 
pect large differences for different cortical areas.

There do seem to be important variations in the synaptogenetic curve, however-not large differences across areas, but discontinuities that, by hypothesis, relate to the cognitive-developmental levels. According to Figure 6 in Goldman-Rakic's article, synaptic density first rose above the normal adult level in rhesus between birth and 1 month of age. In some areas, it then leveled off for several months, while in others it continued to rise to a peak at approximately 2 months of age before leveling off. Next, in some areas, it rose to a new peak at $4-41 / 2$ months of age. Finally, after approximately $4 \frac{1}{2}$ months of age, it began to gradually decrease until after many months it reached the adult level.

The available data thus indicate a peak at 2 months, a peak at 4-41/2 months, and probably an earlier leveling off at approximately 1 month of age. Of course, limits on ages sampled as well as sample size preclude firm conclusions about the exact forms of the developmental curves and the consistency of these apparent discontinuities across cortical regions. Nevertheless, these three discontinuities are consistent with the proposed model. There seem to be discontinuities in the synaptogenetic curves at the approximate ages for emergence of the three sensorimotor levels in rhesus.

\section{The Brain-Growth Model}

Several scholars have hypothesized that major brain changes occur with each cognitive-developmental level (Epstein, 1974; Fischer \& Pipp, 1984; Gibson, 1977; White, 1970). The apparent connection between concurrent synaptogenesis and the three sensorimotor levels in rhesus may be one such relation. If that relation holds for human infants as well as rhesus, then the synaptogenetic spurt in human infants will show discontinuities at approximately 4,8 , and 13 months, with emergence of the three sensorimotor levels. In addition, human infants will show a fourth discontinuity at approximately 20 months. Available data on human synaptogenesis are limited, but they do suggest that concurrent synaptogenesis peaks at 8-12 months in the visual cortex and then gradually declines-a pattern similar to that predicted from the rhesus data (Huttenlocher, de Courten, Garey, \& van der Loos, 1982). In the frontal cortex, on the other hand, it appears to extend for a longer period-peaking at 1-2 years and not decreasing substantially until after 7 years of age (Huttenlocher, 1979).
A more modest extension of synaptogenesis presumably occurs for the great apes as well, since they also seem to reach the level of single representations, although in a limited form (Chevalier-Skolnikoff, 1977; Parker \& Gibson, 1979).

Brain-wave patterns are a good candidate for testing the brain-growth hypothesis. They show strong developmental change that can be reliably measured, and they index a form of brain activity that seems to reflect changes in brain functioning. The electroencephalogram, evoked potentials, and brain metabolism all show major changes at the ages for the developmental levels (Chugani \& Phelps, 1986; Dreyfus-Brisac, 1978; Emde, Gaensbauer, \& Harmon, 1976; Kagan, 1982; Woodruff, 1978). For example, in the electroencephalogram, new peak frequencies develop at approximately 4 and 8 months of age, especially in the occipital-parietal area (Hagne, Persson, Magnusson, \& Petersen, 1973).

In addition, we have data suggesting general spurts in brain size during these age periods. Subjects were a cross-sectional sample of over a thousand infants measured at ages distributed throughout the first year of life by Bonnie Camp at the Colorado Health Sciences Center. For example, the infants showed a strong, statistically reliable spurt in head growth between 7 and 8 months, the age of emergence of the second sensorimotor level (Fischer, Camp, Pipp, \& Rose, 1986). That is, mean head circumference increased $2.7 \%(11.8 \mathrm{~mm})$ between 7 and 8 months, while it increased only $1.5 \%(6.5 \mathrm{~mm})$ between 6 and 7 months and $0.1 \%(0.6 \mathrm{~mm})$ between 8 and 9 months. This spurt in head growth was the largest for any month after 4 months of age. (The head grows fast early in the first year and then slows down.) Note that 7-8 months is the same age that the second sensorimotor level emerges.

Between 3 and 4 months, when the first level emerges, there was a spurt of $3.1 \%$ (12.4 $\mathrm{mm}$ ). Analysis of week-by-week changes suggests that this spurt is focused at 15-17 weeks. Data are not yet available to determine whether a similar head-growth spurt occurs with the emergence of the third level at 12-13 months or the fourth level at 18-21 months.

Of course, caution must be exercised in interpreting the head-circumference data. First, head circumference is not a direct measure of brain size, although there is a strong correlation between the two in human beings (Winick \& Rosso, 1969). Second, although in- 
creases in brain size could be produced by concurrent synaptogenesis, they could also be produced by many other brain events, such as the growth of myelin in the cortex during the same period (Yakovlev \& Lecours, 1967). Third, the spurts can be seen reliably only in a large sample of children, not in individual growth curves. Camp has longitudinal data for over 30 infants, and the individual curves show wide variations, presumably arising from factors such as illness, nutrition, hair growth, and measurement error. Lampl and Emde (1983) report similar individual variations in growth curves. Fourth, a note of caution is needed. A correlation between increase in head size and onset of developmental level does not mean that head size in general correlates with intelligence as measured by intelligence tests. The two correlations are independent, because increase in head size at a specific age interval need not relate to total head size.

According to the brain-growth hypothesis, spurts in brain change will occur with the emergence of each developmental level. Research to date indicates that there are at least four sensorimotor levels in human infancy and at least three in rhesus. Additional levels between those already identified seem unlikely, since careful investigations have uncovered no evidence for additional discontinuities (e.g., Corrigan, 1983; McCall et al., 1977). However, before the first level (single actions) additional levels have been hypothesized (Fischer, 1980; Fischer \& Hogan, in press). The existence of such early levels would have important implications for research on synaptogenesis or other brain changes, because it would mean that studies must be designed to detect a rapid-fire series of discontinuities. The greater the number of developmental levels, the more frequently ages must be sampled to detect those levels and the more discriminations developmental scales must make.

After infancy, human beings develop intellectual capacities that are never seen in other primates. Cognitive-developmental theorists predict between three and ten additional levels after those of infancy (Biggs \& Collis, 1982; Case, 1985; Fischer, 1980; Halford, 1982). Empirical evidence supports at least four periods of rapid behavioral change-at approximately 4 years, 6-7 years, 10-12 years, and 14-16 years (Fischer \& Silvern, 1985). As always, the exact ages vary with the particular tasks and assessment criteria.
Brain electrical activity changes systematically with these later cognitive-developmental levels too (Dustman \& Beck, 1969; Epstein, 1980; Fischer \& Pipp, 1984). These findings seem to imply that there are basic changes in brain functioning, analogous to concurrent synaptogenesis, that occur for each developmental level. What might these changes be for the later levels?

In terms of the brain-growth model, the most likely neural foundation for the later levels is formation of a group of new synapses in a limited cortical region, even though overall synaptic density is not increasing. Although brain scientists used to believe that no new synapses formed after infancy, recent research indicates that new synapses can form later in development, as reported by Greenough, Black, and Wallace (1987, in this issue). Another foundation consistent with the model is a spurt in the pruning of synapses rather than the formation of new ones. Finally, of course, the later levels may be of a different sort from the earlier ones, depending not on synaptic change but on other brain processes such as myelin formation, which continues into early adulthood (Yakovlev \& Lecours, 1967).

\section{Conclusion: The Prefrontal Cortex in the Whole Brain}

Goldman-Rakic's findings clearly provide fertile ground for relating brain development with cognitive development. Indeed, the hypothesized relations between concurrent synaptogenesis and infant cognitive development lead straightforwardly to a specific, extensive research program for mapping out possible neural bases of cognitive development.

In the simple model I have suggested, each developmental level is marked by not only behavioral discontinuities but also discontinuities in synaptogenesis and developing brain electrical activity. Of course, the pattern may not prove to be so simple, but whatever the relations between cognitive developments and brain-growth patterns, the results will shed light on the neural foundations of cognitive change.

Notice, however, that I have said little about an important part of Goldman-Rakic's findings. Besides uncovering concurrent synaptogenesis, she and her colleagues have also described a basic part of the wiring diagram for the delayed-response task in the prefrontal cortex. They have even found a type of neuron that specifically increases its firing 
rate during the delay period in that task. From these findings, they originally expected to discover a synaptogenetic change specific to the prefrontal area at the age when rhesus are beginning to solve the delayed-response task. Instead, they found concurrent synaptogenesis-spurts followed by drops in all areas of the cortex during the same age period.

This global pattern of cortical development appears to make sense from a cognitivedevelopmental perspective. The cognitive changes that occur with each developmental level are general ones, affecting a wide range of behaviors. Other brain evidence also supports the global pattern: There are discontinuities in the developmental functions for the electroencephalogram and even for brain (head) size in infancy. The prefrontal cortex is central to performance on the delayedresponse task. But as I believe GoldmanRakic would agree, it works with other cortical areas to produce changes in general cognitive capacity.

\section{References}

Bates, E., Benigni, L., Bretherton, I., Camaioni, L., \& Volterra, V. (1979). The emergence of symbols. New York: Academic Press.

Bertenthal, B. I., Campos, J. J., \& Haith, M. M. (1980). Development of visual organization: The perception of subjective contours. Child Development, 51, 1072-1080.

Biggs, J., \& Collis, K. (1982). A system for evaluating learning outcomes: The SOLO taxonomy. New York: Academic Press.

Bloom, L. (1973). One word at a time. The Hague: Mouton.

Bornstein, M. H., \& Sigman, M. D. (1986). Continuity in mental development from infancy. Child Development, 57, 251-274.

Case, R. (1985). Intellectual development: Birth to adulthood. New York: Academic Press.

Chevalier-Skolnikoff, S. (1977). A Piagetian model for describing and comparing socialization in monkey, ape, and human infants. In S. Chevalier-Skolnikoff \& F. E. Poirier (Eds.), Primate bio-social development: Biological, social, and ecological determinants (pp. 159188). New York: Garland.

Chugani, H. T., \& Phelps, M. E. (1986). Maturational changes in cerebral function in infants determined by ${ }^{18}$ FDG Positron Emission Tomography. Science, 231, 840-843.

Conel, J. L. (1939-1963). The postnatal development of the human cerebral cortex (7 vols.). Cambridge, MA: Harvard University Press.

Corrigan, R. (1983). The development of representational skills. In K. W. Fischer (Ed.), Levels and transitions in children's development
(New Directions for Child Development No. 21, pp. 51-64). San Francisco: Jossey-Bass, 1983.

Diamond, A. (1985). Development of the ability to use recall to guide action, as indicated by infants' performance on $\mathrm{A} \overline{\mathrm{B}}$. Child Development, 56, 868-883.

Diamond, A., \& Goldman-Rakic, P. (1983). Comparison of performance on a Piagetian object permanence task in human infants and rhesus monkeys: Evidence for involvement of prefrontal cortex. Society for Neuroscience $A b$ stracts, $\mathbf{5}, 85$.

Diamond, A., \& Goldman-Rakic, P. (1986). Comparative development in human infants and rhesus monkeys of cognitive functions that depend on prefrontal cortex. Society for Neuroscience Abstracts, Vol. 6.

Dreyfus-Brisac, C. (1978). Ontogenesis of brain bioelectrical activity and sleep organization in neonates and infants. In F. Falkner \& J. M. Tanner (Eds.), Human growth 3: Neurobiology and nutrition. New York: Plenum.

Dustman, R. E., \& Beck, E. C. (1969). The effects of maturation and aging on the waveform of visually evoked potentials. Electroencephalogram and Clinical Neurophysiology, 265, 2-11.

Emde, R., Gaensbauer, T., \& Harmon, R. (1976). Emotional expression in infancy: A biobehavioral study. Psychological Issues (Vol. 10, No. 37). New York: International Universities Press.

Epstein, H. T. (1974). Phrenoblysis: Special brain and mind growth periods. Developmental Psychobiology, 7, 207-224.

Epstein, H. T. (1980). EEG developmental stages. Developmental Psychobiology, 13, 629-631.

Fischer, K. W. (1980). A theory of cognitive development: The control and construction of hierarchies of skills. Psychological Review, 87, 477-531.

Fischer, K. W. (1982). Human cognitive development in the first four years. Behavioral and Brain Sciences, 5, 282-283.

Fischer, K. W., Camp, B., Pipp, S. L., \& Rose, S. (1986). Spurts in head circumference in human infants. Unpublished manuscript.

Fischer, K. W., \& Canfield, R. L. (1986). The ambiguity of stage and structure in behavior: Person and environment in the development of psychological structures. In I. Levin (Ed.), Stage and structure: Reopening the debate (pp. 246267). New York: Plenum.

Fischer, K. W., \& Hogan, A. (in press). Sources of variation in the development of actions in infancy. In J. Lockman \& N. Hazen (Eds.), Action in social context: Perspectives on early development. New York: Plenum.

Fischer, K. W., \& Jennings, S. (1981). The emergence of representation in search. Developmental Review, 1, 18-30. 
Fischer, K. W., \& Pipp, S. L. (1984). Processes of cognitive development: Optimal level and skill acquisition. In R. J. Sternberg (Ed.), Mechanisms of cognitive development (pp. 45-80). San Francisco: W. H. Freeman.

Fischer, K. W., Pipp, S. L., \& Bullock, D. (1984). Detecting discontinuities in development: Method and measurement. In R. Emde \& R. Harmon (Eds.), Continuities and discontinuities in development (pp. 95-121). New York: Plenum.

Fischer, K. W., \& Roberts, R. J., Jr. (1986). The development of classification skills in the preschool years: Developmental level and errors. Unpublished manuscript.

Fischer, K. W., \& Silvern, L. (1985). Stages and individual differences in cognitive development. Annual Review of Psychology, 36, 613-648.

Flavell, J. (1982). On cognitive development. Child Development, 53, 1-10.

Gelman, R. (1978). Cognitive development. Annual Review of Psychology, 29, 297-332.

Gibson, K. R. (1977). Brain structure and intelligence in macaques and human infants from a Piagetian perspective. In S. ChevalierSkolnikoff \& F. E. Poirier (Eds.), Primate biosocial development: Biological, social, and ecological determinants (pp. 113-158). New York: Garland.

Goldman-Rakic, P. (1986). Circuitry of the prefrontal cortex and the regulation of behavior by representational knowledge. In F. Plum \& V. Mountcastle (Eds.), Handbook of physiology. Bethesda, MD: American Physiological Society.

Goldman-Rakic, P. S. (1987). Development of cortical circuitry and cognitive function. Child Development, 58, 601-622.

Greenough, W. T., Black, J. E., \& Wallace, C. S. (1987). Experience and brain development. Child Development, 58, 539-559.

Hagne, I., Persson, J., Magnusson, R., \& Petersen, I. (1973). Spectral analysis via fast Fourier transform of waking EEG in normal infants. In P. Kellaway \& I. Petersen (Eds.), Automation of clinical electroencephalography (pp. 103143). New York: Raven.

Halford, G. S. (1982). The development of thought. Hillsdale, NJ: Erlbaum.

Huttenlocher, P. (1979). Synaptic density in human frontal cortex-developmental changes and effects of aging. Brain Research, 163, 195-205.

Huttenlocher, P., de Courten, C., Garey, L. J., \& van der Loos, H. (1982). Synaptogenesis in human visual cortex-evidence for synapse elimination during normal development. Neuroscience Letters, 33, 247-252.

Jackson, E., Campos, J. J., \& Fischer, K. W. (1978). The question of decalage between object permanence and person permanence. Developmental Psychology, 14, 1-10.
Kagan, J. (1982). Psychological research on the human infant: An evaluative summary. New York: W. T. Grant Foundation.

Lampl, M., \& Emde, R. N. (1983). Episodic growth in infancy: A preliminary report on length, head circumference, and behavior. In $\mathrm{K}$. W. Fischer (Ed.), Levels and transitions in children's development (New Directions for Child Development, No. 21, pp. 21-36). San Francisco: Jossey-Bass.

McCall, R. B. (1983). Exploring developmental transitions in mental performance. In $\mathrm{K}$. W. Fischer (Ed.), Levels and transitions in children's development (New Directions for Child Development, No. 21, pp. 65-80). San Francisco: Jossey-Bass.

McCall, R. B., Eichorn, D. H., \& Hogarty, P. S. (1977). Transitions in early mental development. Monographs of the Society for Research in Child Development, 42(3, Serial No. 171).

Parker, S. T., \& Gibson, K. R. (1979). A developmental model of the evolution of language and intelligence in early hominids. Behavioral and Brain Sciences, 2, 367-381.

Piaget, J. (1951). Play, dreams, and imitation in childhood (C. Gattegno \& F. M. Hodgson, trans.). New York: Harcourt Brace. (Original work published 1946)

Piaget, J. (1954). The construction of reality in the child (M. Cook, trans.). New York: Basic. (Original work published 1937)

Rakic, P., Bourgeois, J.-P., Eckenhoff, M. F., Zecevic, N., \& Goldman-Rakic, P. (1986). Concurrent overproduction of synapses in diverse regions of the primate cerebral cortex. Science, 232, 232-235.

Ramsay, D. S. (1984). Onset of duplicated syllable babbling and unimanual handedness in infancy: Evidence for developmental change in hemispheric specialization? Developmental Psychology, 20, 64-71.

Roberts, R. J., Jr. (1981). Errors and the assessment of cognitive development. In K. W. Fischer (Ed.), Cognitive development (New Directions for Child Development, No. 12, pp. 69-78). San Francisco: Jossey-Bass.

Seibert, J. M., Hogan, A. E., \& Mundy, P. C. (1984). Mental age and cognitive stage in young handicapped and at-risk children. Intelligence, 8 , 11-29.

Uzgiris, I. C. (1976). Organization of sensorimotor intelligence. In M. Lewis (Ed.), Origins of intelligence: Infancy and early childhood (pp. 123-164). New York: Plenum.

Uzgiris, I. C., \& Hunt, J. McV. (1975). Assessment in infancy: Ordinal scales of psychological development. Urbana: University of Illinois Press.

Watson, M. W., \& Fischer, K. W. (1977). A developmental sequence of agent use in late infancy. Child Development, 48, 828-835. 


\section{Child Development}

White, S. H. (1970). Some general outlines of the matrix of developmental changes between five and seven years. Bulletin of the Orton Society, 20, 41-57.

Winick, M., \& Rosso, P. (1969). Head circumference and cellular growth of the brain in normal and marasmic children. Journal of Pediatrics, 74, 774-778.

Wohlwill, J. F. (1973). The study of behavioral development. New York: Academic Press.
Woodruff, D. S. (1978). Brain electrical activity and behavior relationships over the lifespan. In P. B. Baltes (Ed.), Life-span development and behavior (Vol. 1, pp. 111-179). New York: Academic Press.

Yakovlev, P. I., \& Lecours, A. R. (1967). The myelogenetic cycles of regional maturation of the brain. In A. Minkowsky (Ed.), Regional development of the brain in early life (pp. 3-70). Oxford: Blackwell. 
http://www.jstor.org

\title{
LINKED CITATIONS
}

\author{
- Page 1 of 3 -
}

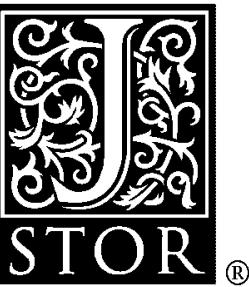

You have printed the following article:

\author{
Relations between Brain and Cognitive Development \\ Kurt W. Fischer \\ Child Development, Vol. 58, No. 3. (Jun., 1987), pp. 623-632. \\ Stable URL: \\ http://links.jstor.org/sici?sici=0009-3920\%28198706\%2958\%3A3\%3C623\%3ARBBACD\%3E2.0.CO\%3B2-6
}

This article references the following linked citations. If you are trying to access articles from an off-campus location, you may be required to first logon via your library web site to access JSTOR. Please visit your library's website or contact a librarian to learn about options for remote access to JSTOR.

\section{References}

Development of Visual Organization: The Perception of Subjective Contours

Bennett I. Bertenthal; Joseph J. Campos; Marshall M. Haith

Child Development, Vol. 51, No. 4. (Dec., 1980), pp. 1072-1080.

Stable URL:

http://links.jstor.org/sici?sici=0009-3920\%28198012\%2951\%3A4\%3C1072\%3ADOVOTP\%3E2.0.CO\%3B2-E

\section{Continuity in Mental Development from Infancy}

Marc H. Bornstein; Marian D. Sigman

Child Development, Vol. 57, No. 2. (Apr., 1986), pp. 251-274.

Stable URL:

http://links.jstor.org/sici?sici=0009-3920\%28198604\%2957\%3A2\%3C251\%3ACIMDFI\%3E2.0.CO\%3B2-7

\author{
Maturational Changes in Cerebral Function in Infants Determined by 18 FDG Positron \\ Emission Tomography \\ Harry T. Chugani; Michael E. Phelps \\ Science, New Series, Vol. 231, No. 4740. (Feb. 21, 1986), pp. 840-843. \\ Stable URL: \\ http://links.jstor.org/sici?sici=0036-8075\%2819860221\%293\%3A231\%3A4740\%3C840\%3AMCICFI\%3E2.0.CO\%3B2-9
}


http://www.jstor.org

\section{LINKED CITATIONS}

- Page 2 of 3 -

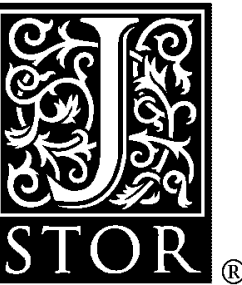

Development of the Ability to Use Recall to Guide Action, as Indicated by Infants' Performance on AB\#

Adele Diamond

Child Development, Vol. 56, No. 4. (Aug., 1985), pp. 868-883.

Stable URL:

http://links.jstor.org/sici?sici=0009-3920\%28198508\%2956\%3A4\%3C868\%3ADOTATU\%3E2.0.CO\%3B2-P

\section{On Cognitive Development}

John H. Flavell

Child Development, Vol. 53, No. 1. (Feb., 1982), pp. 1-10.

Stable URL:

http://links.jstor.org/sici?sici=0009-3920\%28198202\%2953\%3A1\%3C1\%3AOCD\%3E2.0.CO\%3B2-N

\section{Development of Cortical Circuitry and Cognitive Function}

Patricia S. Goldman-Rakic

Child Development, Vol. 58, No. 3. (Jun., 1987), pp. 601-622.

Stable URL:

http://links.jstor.org/sici?sici=0009-3920\%28198706\%2958\%3A3\%3C601\%3ADOCCAC\%3E2.0.CO\%3B2-O

\section{Experience and Brain Development}

William T. Greenough; James E. Black; Christopher S. Wallace

Child Development, Vol. 58, No. 3. (Jun., 1987), pp. 539-559.

Stable URL:

http://links.jstor.org/sici?sici=0009-3920\%28198706\%2958\%3A3\%3C539\%3AEABD\%3E2.0.CO\%3B2-J

\section{Transitions in Early Mental Development}

Robert B. McCall; Dorothy H. Eichorn; Pamela S. Hogarty; Ina C. Uzgiris; Earl S. Schaefer Monographs of the Society for Research in Child Development, Vol. 42, No. 3, Transitions in Early Mental Development. (1977), pp. 1-108.

Stable URL:

http://links.jstor.org/sici?sici=0037-976X\%281977\%2942\%3A3\%3C1\%3ATIEMD\%3E2.0.CO\%3B2-B

Concurrent Overproduction of Synapses in Diverse Regions of the Primate Cerebral Cortex Pasko Rakic; Jean-Pierre Bourgeois; Maryellen F. Eckenhoff; Nada Zecevic; Patricia S. Goldman-Rakic

Science, New Series, Vol. 232, No. 4747. (Apr. 11, 1986), pp. 232-235.

Stable URL:

http://links.jstor.org/sici?sici=0036-8075\%2819860411\%293\%3A232\%3A4747\%3C232\%3ACOOSID\%3E2.0.CO\%3B2-7 
http://www.jstor.org

\section{LINKED CITATIONS \\ - Page 3 of 3 -}

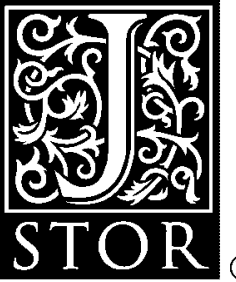

A Developmental Sequence of Agent Use in Late Infancy

Malcolm W. Watson; Kurt W. Fischer

Child Development, Vol. 48, No. 3. (Sep., 1977), pp. 828-836.

Stable URL:

http://links.jstor.org/sici?sici=0009-3920\%28197709\%2948\%3A3\%3C828\%3AADSOAU\%3E2.0.CO\%3B2-8 